Tropical Journal of Pharmaceutical Research December 2016; 15 (12): 2713-2718

ISSN: 1596-5996 (print); 1596-9827 (electronic)

(1) Pharmacotherapy Group, Faculty of Pharmacy, University of Benin, Benin City, 300001 Nigeria.

All rights reserved.

Available online at http://www.tjpr.org

Original Research Article

http://dx.doi.org/10.4314/tjpr.v15i12.25

\title{
A comparative study of voluntarily reported medication errors among adult patients in intensive care (IC) and non- IC settings in Riyadh, Saudi Arabia
}

\author{
Shmeylan A AlHarbi ${ }^{1,2}$, Nasser Mahdi Al-Qhtani ${ }^{1}$, Rami Bustami ${ }^{2}$, Hind \\ Almodaimegh $^{1,2}$, Abdulmalik M Alkatheri ${ }^{1,2}$, Hind A Al Badali ${ }^{1}$, Yousef $\mathrm{H}$ Al \\ Awlah $^{1,2}$, Saleh Aldekhael ${ }^{1,2}$, Waleed Al Tuwaijri ${ }^{3}$, Salah M AbuRuz ${ }^{2,4}$, \\ Abdulkareem M Albekairy ${ }^{1,2^{\star}}$ \\ ${ }^{1}$ Pharmaceutical Care Services, King Abdulaziz Medical City, ${ }^{2}$ Pharmacy Practice Department, College of Pharmacy, King \\ Saud Bin Abdulaziz University for Health Sciences, ${ }^{3}$ Department of Pediatric, King Abdulaziz Medical City, Riyadh, Saudi \\ Arabia, ${ }^{4}$ College of Pharmacy, University of Jordan, Amman, Jordan
}

*For correspondence: Email: bekairya@ngha.med.sa

Received: 12 August 2016

Revised accepted: 24 November 2016

\begin{abstract}
Purpose: To investigate the risk factors associated with medication errors and to compare the incidence and types of voluntarily reported medication errors among adult intensive care unit (ICU) and non-ICU patients at King Abdulaziz Medical City, Riyadh, Saudi Arabia.

Methods: The design of this study was retrospective. All voluntarily reported medication errors involving adult patients ( $\geq 18$ years) who were admitted into King Abdulaziz Medical City during the study period (January 2012 to June 2013) were included in the study. Reported medication errors were classified as ICU or non-ICU errors. Medication errors were also classified according to the node of medication use, harm category, and type of medication errors.

Results: A total of 31,399 patients admitted into the hospital were included in the study, with 1,966 (6 $\%)$ admitted into the ICU and 29,433 (94\%) admitted into the non-ICU units. Overall, the incidence of medication errors was $1.2 \%(390 / 31,399), 1$. Over half of the errors were administration-related $(51 \%)$. The incidence of medication errors was $5.5 \%(108 / 1,966)$ in ICU compared with $0.96 \%(282 / 29,433)$ in non-ICU units $(p<0.001$. In both settings, prescribing errors, delay in drug administration and dispensing extra dose were the most common medication errors. Higher risk for medication errors was significantly associated with admission into ICU vs. non-ICU units [OR = 5.24, $95 \%$ Cl: (4.12, 6.65); $p<$ $0.001]$ and with patients' age $\geq 60$ vs. $<60$ years [OR =1.48, $95 \% \mathrm{Cl}:(1.19,1.83) ; p<0.001]$.

Conclusion: Medication errors are common in the health facility and occur during all stages of medication use from prescribing to administration. Higher risk for medication errors is associated with admission into the ICU and with patients' age $\geq 60$. Physician, pharmacists, and nurses need to be vigilant, up-to-date, and continuously trained to reduce the incidence of medication errors.
\end{abstract}

Keywords: Medication errors, Voluntary reporting, Intensive care unit, Hospital setting

Tropical Journal of Pharmaceutical Research is indexed by Science Citation Index (SciSearch), Scopus, International Pharmaceutical Abstract, Chemical Abstracts, Embase, Index Copernicus, EBSCO, African Index Medicus, JournalSeek, Journal Citation Reports/Science Edition, Directory of Open Access Journals (DOAJ), African Journal Online, Bioline International, Open-J-Gate and Pharmacy Abstracts

\section{INTRODUCTION}

The focus on patient safety and the efforts for its improvement have been substantially growing during the past several decades. In 1999, the Institute of Medicine (IOM) released its milestone report on patient safety "To err is human: Building a safer health care system" 
which estimated that around 44,000 to 98,000 people in the United States die every year due to preventable medical errors. Among these fatal medical errors, about 7,000 deaths were attributed to medication-related errors [1].

Medication errors are common in hospital settings and can lead to significant incidence of adverse drug events (ADEs) [2]. The incidence of ADE's in the intensive care units (ICU) is almost double that occurring in general care units [3]. About $47 \%$ of ADEs occur in the ICU and $78 \%$ of the serious ADEs are caused by medications [4]. This high incidence of serious ADEs could be the result of complex therapy regimens and the physiological and disease state of ICU patients [5]. Intravenous medications are more likely to be administered in critical care as compared to noncritical care settings which might contribute to the increased incidence and magnitude of medication errors [6]. While most medication errors tend to occur during the administration process, a higher incidence of such errors was observed in the in ICU compared to Non-ICU setting (44 and $33 \%$, respectively). On the other hand, errors in the dispensing phase were found to be less reported in ICU than Non-ICU setting (9 and $22 \%$, respectively) [7].

The impact of medication errors on patients, their relatives, and the healthcare organization is enormous both financially and personally. The cost of preventable medication errors was estimated to be $\$ 2.8$ million per year in a 700 bed teaching hospital [8]. The length of hospital stay $\mathrm{w}$ increased by $1 \%$ due to ICU medication errors compared to $0.4 \%$ due to non-ICU errors in one study [9].

The purpose of this study is to investigate the risk factors associated with medications errors and to compare the incidence and type of voluntarily reported medication errors in adult IC patients to that in adult non-IC patients. Only few studies have reported such a comparison $[7,9]$.

\section{METHODS}

\section{Subjects and settings}

The study was retrospective and conducted at King Abdulaziz Medical City, Riyadh, Saudi Arabia which is a large, 1025 bed tertiary care hospital in Riyadh, Saudi Arabia.

All medication errors which were reported on adult patients (18 years and older) who were admitted to the hospital wards during the study period (January 2012 to June 2013) were included in the study.

The study was approved by the institutional review board at King Abdullah International Medical Research Center (KAIMRC).

\section{Medication errors reporting at the study site}

A medication error was defined in this study as "an error in the process of prescribing, dispensing, preparing, administering, monitoring or providing medicine advice, regardless of whether any harm occurred" [1].

The medication error reporting in the study site is voluntary. The hospital administration encourages voluntary reporting of errors. In the case of actual/suspected medication error, the staff (usually a physician, a nurse, or a pharmacist) should fill in a medication error report that includes all related clinical and demographic information. The report is then submitted to the medication safety committee which evaluates the submitted report for accuracy, severity, clinical impact and then makes a decision on the necessary action to avoid future errors. The medication safety committee is composed of physicians, pharmacists, and nurses.

The hospital has adopted a "Just culture" with regard to medication errors since three years before this study. "Just culture" is a culture in which front-line operators and others are not punished for their actions, omissions or decisions that are commensurate with their experience and training, whereas gross negligence, willful violations, and destructive acts are not tolerated [10]. A "Just Culture" is not a "blame-free" culture. It is rather a middle ground between a blame-free culture where providers have no personal accountability and a culture where providers are blamed for all mistakes.

\section{Data collection}

Medication errors that were voluntarily reported and approved by the medication safety committee were classified as IC or non-IC errors. Patient demographic information and medication error-related data were collected from patients' medical records and from medication safety committee reports. These data include age $(<60$ years, $>60$ years), admission year, month of reported error, reported error day (weekday, weekend), the node of medication use (prescribing, documenting/transcribing, dispensing, administering, and monitoring), harm category (category A-I) where category I 
indicates death, and type of medication error (prescribing error, omission error, wrong time, unauthorized drug, improper dose, wrong dosage form, wrong drug preparation, wrong administration technique, deteriorated drug, monitoring error, compliance error, and other medication error). Specific types of the "other" category include system error, documentation error, delay in dose, extra doses /wastage, and wrong practice/policy violation.

\section{Data analysis}

All of the study data were categorical and were expressed as frequency (proportion). The incidence of non-IC and IC medication errors was expressed as proportions and also as a rate per 1000 admissions. The latter is calculated by dividing the number of medication errors by the total number of admissions and multiplying the result by 1000 . Non-IC and IC medication errors incidence rates and types were evaluated and compared by the demographic and clinical factors using the chi-square test. Logistic regression analysis was used to identify factors affecting the likelihood of medication errors. The backward elimination procedure was used to obtain the final model. Statistical significance was considered at $p<0.05$. All statistical analyses were performed using SPSS 21.0 (IBM, USA).

\section{RESULTS}

\section{Demographic information}

A total of 31,399 adult patients' were admitted to the hospital during the study period. All of the admissions were considered eligible for inclusion in the study. The number of admissions into IC was 1966 (6\%) and 29433 (94\%) were admitted into non-IC units.

\section{Medication errors}

A total of 390 medication errors were voluntarily reported during the study period. Table 1 demonstrates comparisons of incidence and types of medication errors between the ICU and non-ICU settings. All comparisons were statistically significant. Overall, the incidence of medication errors was $1.2 \%(390 / 31,399)$ which is equivalent to 12 per 1000 patients. Over half of the reported errors were administration-related errors $(51 \%)$. Only $9 \%$ of the reported medication errors were categorized as harm categories $\mathrm{C}$ to $\mathrm{I}$, while the vast majority were categorized as harm categories A or B (91\%).
The incidence of medication errors was $5.5 \%$ $(108 / 1,966)$ (equivalent to 55 errors per 1000 admissions) in the ICU compared with $0.96 \%$ $(282 / 29,433)$ (equivalent to 9.6 errors per 1000 admissions) in the non-ICU units, $p<0.001$. The incidence of medication errors was also significantly different by the age group; where the incidence was $1.97 \%(164 / 8,343)$ (equivalent to 19.7 errors per 1000 admissions) among patients aged $\geq 60$ years vs. $0.98 \%$ (226/23056) (equivalent to 9.8 errors per 1000 admissions) among those aged $<60$ years $(p<0.001)$.

The incidence of medication errors was also significantly different by the age group among patients admitted into non-IC units (incidence of medication errors was $1.5 \%(109 / 7,181)$ for patients aged $\geq 60$ years vs. $0.8 \%(173 / 22,252)$ for those aged $<60 ; p<0.001)$. However, the incidence of medication errors was not different by age among patients admitted into IC units (incidence of medication errors was $4.7 \%$ $(55 / 1,162)$ for patients aged $\geq 60$ years vs. $6.6 \%$ $(53 / 804)$ for those aged $<60 ; p>0.05)$.

In both, IC and non-IC settings, prescribing errors, delay in drug administration and dispensing extra dose were the most common medication errors. The most common medication error was prescribing errors in the non-IC units, while in the IC settings, delay in drug administration was the most common.

The most common medication use phase during which medication errors were detected was the medication administration phase in both IC and non-IC settings (Table 1 ).

\section{Risk factors for medication errors}

Results from the logistic regression analysis in Table 2 showed that higher risk of medication errors was significantly associated with admission into IC vs. non-IC units [OR = 5.24, 95 $\%$ Cl: $(4.12,6.65) ; p<0.001]$ and with patients age $\geq 60$ vs. $<60$ years $[\mathrm{OR}=1.48,95 \% \mathrm{Cl}$ : $(1.19,1.83) ; p<0.001]$.

\section{DISCUSSION}

The results of this study indicated that the incidence of medication errors in the ICU was five times higher than that in the non-ICU setting $(O R=5.24)$. This finding is consistent with the literature [11].

The higher incidence of medication errors in the ICU may be related to the severity of illness of 
Table 1: Comparison of medication error incidence between ICU and non-ICU patients by demographic and clinical factors

\begin{tabular}{|c|c|c|c|}
\hline Factor & $\begin{array}{c}\text { All patients } \\
\mathrm{N}=31,399(100 \%)\end{array}$ & $\begin{array}{c}\text { Non-ICU patients } \\
\mathrm{N}=29,433(94 \%)\end{array}$ & $\begin{array}{l}\text { ICU patients } \\
\mathrm{N}=1,966(6 \%)\end{array}$ \\
\hline $\begin{array}{l}\text { Medication errors } \\
\text { Age group, } \mathrm{n}(\%)\end{array}$ & $390(1.2)$ & $282(0.96)$ & $108(5.5)$ \\
\hline $\begin{array}{l}<60 \text { years } \\
(\mathrm{N}=22252 \text { non- } \mathrm{ICU}, \mathrm{N}=804 \mathrm{ICU})\end{array}$ & $226(0.72)$ & $173(0.59)$ & $53(2.7)$ \\
\hline $\begin{array}{l}\geq 60 \text { years } \\
(\mathrm{N}=7181 \text { non-ICU, } N=1162 \mathrm{ICU})\end{array}$ & $164(0.52)$ & $109(0.37)$ & $55(2.8)$ \\
\hline \multicolumn{4}{|l|}{ Day of week, N (\%) } \\
\hline $\begin{array}{l}\text { Weekday } \\
\text { Weekend }\end{array}$ & $\begin{array}{l}294(0.94) \\
96(0.31)\end{array}$ & $\begin{array}{l}215(0.73) \\
67(0.23)\end{array}$ & $\begin{array}{l}79(4.02) \\
29(1.48)\end{array}$ \\
\hline \multicolumn{4}{|l|}{ Type of medication error, $N(\%)$} \\
\hline $\begin{array}{l}\text { Prescription error } \\
\text { Improper dose } \\
\text { Wrong drug preparation } \\
\text { Delay in drug administration } \\
\text { Extra dose dispensed } \\
\text { Wrong practice / Policy violation } \\
\text { Other }\end{array}$ & $\begin{array}{l}74(0.24) \\
16(0.05) \\
26(0.08) \\
45(0.14) \\
59(0.19) \\
31(0.1) \\
139(0.44)\end{array}$ & $\begin{array}{l}60(0.2) \\
10(0.03) \\
18(0.06) \\
25(0.08) \\
40(0.14) \\
22(0.07) \\
107(0.36)\end{array}$ & $\begin{array}{l}14(0.71) \\
6(0.31) \\
8(0.41) \\
20(1.02) \\
19(0.97) \\
9(0.46) \\
32(1.63)\end{array}$ \\
\hline \multicolumn{4}{|l|}{ Node of medication Use, $\mathrm{N}(\%)$} \\
\hline $\begin{array}{l}\text { Prescribing } \\
\text { Documenting/transcribing } \\
\text { Dispensing } \\
\text { Administering }\end{array}$ & $\begin{array}{c}98(0.31) \\
14(0.04) \\
81(0.26) \\
197(0.63)\end{array}$ & $\begin{array}{c}79(0.27) \\
8(0.03) \\
40(0.14) \\
155(0.53)\end{array}$ & $\begin{array}{l}19(0.97) \\
6(0.31) \\
41(2.09) \\
42(2.14)\end{array}$ \\
\hline \multicolumn{4}{|l|}{ Harm category, N (\%) } \\
\hline $\begin{array}{l}\text { Category A } \\
\text { Category B } \\
\text { Category C } \\
\text { Category D-I }\end{array}$ & $\begin{array}{l}174(0.55) \\
181(0.58) \\
28(0.09) \\
7(0.02) \\
\end{array}$ & $\begin{array}{c}122(0.41) \\
137(0.47) \\
22(0.07) \\
1(0.03) \\
\end{array}$ & $\begin{array}{l}52(2.64) \\
44(2.24) \\
6(0.31) \\
6(0.31) \\
\end{array}$ \\
\hline
\end{tabular}

Table 2: Logistic regression analysis for medication errors. Total number of patients $=31,399$

\begin{tabular}{lccc}
\hline Factor & OR & $95 \% \mathbf{C l}$ & $\boldsymbol{P}$-value \\
\hline $\begin{array}{l}\text { Admission unit } \\
\text { Non-ICU }\end{array}$ & $\begin{array}{c}\text { Reference } \\
\text { ICU }\end{array}$ & $\begin{array}{c}\text { Reference } \\
(4.12,6.65)\end{array}$ & $<0.001$ \\
& 5.24 & & \\
Age group & & & \\
$<60$ years & Reference & Reference & \\
$\geq 60$ years & 1.48 & $(1.19,1.83)$ & $<0.001$ \\
\hline
\end{tabular}

patients admitted [11,12]. Patients admitted to the ICU are typically older and have more critical conditions with impaired organ functions. Moreover, ICU patients are usually receiving several high alert medication and require more intravenous transfusions. Based on the study results, the study site started considering strategies to reduce medication errors including the use of electronic prescription alerts. It has been suggested that the use of electronic prescription alerts may reduce medication errors [13].
An interesting finding from our study is that medication errors reported on weekdays were three times more than those reported during weekends. This could be due to the fact that fewer medications are usually prescribed and processed during weekends where only necessary medications are added or changed. Prescribing errors were the most common type of medication errors reported in the non-ICU setting, while in the ICU, delay in the drug administration was more prevalent than the other error types. Prescribing errors can be reduced through implementing continuous education programs and through training physicians and pharmacist on the concepts of evidence-based medicine [14]. Frequent reporting of the delay in delivering medication to ICU patients may be related to the huge workload. In contrast, staff that work in non-ICU areas are less likely to report such type of incidents because of their less workload where the care is often one staff to four patients and the patients' conditions are less critical. It has been reported that the use of barcode-assisted medication administration 
decreased medication errors related to administration time in adult medical ICUs from 18.8 to $7.5 \%$ [15].

The finding that dispensing extra doses of drugs is common in both the ICU and non-ICU settings is important, based on this result, a study is currently being conducted investigating factors contributing to medication wastage at the hospital.

Over half of medication errors in the current study occurred during the administration phase (51\%), this is similar to the result obtained by Asad et al [7]. Although medication administration errors have the potential to be lifethreatening [16], our analysis revealed that most of the medication errors identified in this study are minor to moderate in severity (harm category A-B). This finding highlights the need for more training for nurses to avoid these errors.

The implementation of "culture of safety" and "just culture" in the study site over the past three years may have helped the staff to understand the importance of patient safety and further enhanced reporting of medication errors. On the other hand, several factors may have contributed to a lower number of reported medication errors such as the implementation of computerized physician order entry in the study site. The use of computerized physician order entry reduced medication prescription errors to $3.4 \%$ of orders in comparison to paper-based orders where the error rate was about $27 \%$ in one study [17]. The study site is also covered by pharmaceutical care services, where clinical pharmacists review and follow up all patients medication from admission till discharge, which may have significantly impacted the incidence of medication errors [18]. The availability of pharmacist support for more than 15 hours per day has been associated with a higher interception of near misses and prescribing errors in one study [19].

\section{Limitations of the study}

A probable limitation to this study is that the medication error reporting in the study institution is a voluntarily reporting system which may reduce the likelihood of reporting of medication errors. Underreporting in a voluntary reporting system could also be related to the lack of adequate reporting systems, fear of litigation, reluctance to report own errors, uncertainty of the clinical importance of the events, and the lack of changes after medication errors reporting [20].

\section{CONCLUSION}

Medication errors are common and occur during all stages of medication use from prescribing to administration. Higher risk for medication errors is associated with admission into the ICU and with patients' age $\geq 60$. Physician, pharmacists, and nurses need to be vigilant, up-to-date, and continuously trained to reduce the incidence of medication errors. Medication errors reporting should be further encouraged to help reduce the harm caused by these errors.

\section{DECLARATIONS}

\section{Acknowledgement}

The authors are grateful to the authorities of King Abdulaziz Medical City, Riyadh, Saudi Arabia for permission to carry out this study.

\section{Conflict of Interest}

No conflict of interest associated with this work.

\section{Contribution of Authors}

The authors declare that this work was done by the authors named in this article and all liabilities pertaining to claims relating to the content of this article will be borne by them.

\section{Open Access}

This is an Open Access article that uses a funding model which does not charge readers or their institutions for access and distributed under the terms of the Creative Commons Attribution License (http://creativecommons.org/ licenses/by/4.0) and the Budapest Open Access Initiative (http://www.budapestopenaccessinitiati ve.org/read), which permit unrestricted use, distribution, and reproduction in any medium, provided the original work is properly credited.

\section{REFERENCES}

1. Kohn $L T$, Corrigan JM, MS D. To Err Is Human: Building a Safer Health System. Washington, DC: National Academy Press, 2000.

2. Delate T, Chester EA, Stubbings TW, Barnes CA. Clinical outcomes of a home-based medication reconciliation program after discharge from a skilled nursing facility. Pharmacotherapy 2008; 28(4): 444-452.

3. Cullen DJ, Sweitzer BJ, Bates DW, Burdick E, Edmondson A, Leape LL. Preventable adverse drug events in hospitalized patients: a comparative study of 
intensive care and general care units. Crit Care Med 1997; 25(8): 1289-1297.

4. Rothschild JM, Landrigan CP, Cronin JW, Kaushal R, Lockley SW, Burdick E, Stone PH, Lilly CM, Katz JT, Czeisler CA, et al. The Critical Care Safety Study: The incidence and nature of adverse events and serious medical errors in intensive care. Crit Care Med 2005; 33(8): 1694-700.

5. Hussain E, Kao E. Medication safety and transfusion errors in the ICU and beyond. Crit Care Clin 2005; 21(1): 91-110, ix.

6. Moss J, Berner E, Bothe O, Rymarchuk I. Intravenous medication administration in intensive care: opportunities for technological solutions. AMIA Annu Symp Proc 2008: 495-499.

7. Asad L, Nishi R, Aliaksei P, Pronovost PJ, Pham JC. National study on the distribution, causes, and consequences of voluntarily reported medication errors between the ICU and non-ICU settings. Crit Care Med 2013; 41(2): 389-398.

8. Bates DW, Spell $N$, Cullen DJ, Burdick E, Laird $N$, Petersen LA, Small SD, Sweitzer BJ, Leape LL. The costs of adverse drug events in hospitalized patients. Adverse Drug Events Prevention Study Group. JAMA 1997; 277(4): 307-311.

9. Kane-Gill SL, Kowiatek JG, Weber RJ. A comparison of voluntarily reported medication errors in intensive care and general care units. Qual Saf Health Care 2010; 19(1): 55-59.

10. European Economic and Social Committee. Open Reporting in Civil and Aviation: Assessment of the EEC'S Prospective role in designing a European role in Just Culture chapter. Available online: http://www.eurocontrol.int/articles/just-culture 2013.

11. Valentin A, Capuzzo M, Guidet B, Moreno R, Metnitz B, Bauer $P$, Metnitz $P$. Errors in administration of parenteral drugs in intensive care units: multinational prospective study. BMJ 2009; 338:b814.

12. van Rosse $F$, Maat $B$, Rademaker $C M$, van Vught $A J$, Egberts AC, Bollen CW. The effect of computerized physician order entry on medication prescription errors and clinical outcome in pediatric and intensive care: a systematic review. Pediatrics 2009; 123(4): 1184-1190.

13. Manuel Vélez-Díaz-Pallarés MR, Elena Villamañán, Yolanda Larrubia, Erica Wagner, Alicia Herrero. Impact of electronic prescription alerts on medication errors related to vitamin $K$ antagonists in hospitalised patients. Eur J Hosp Pharm 2014; 21(1): 29-33.

14. Aburuz $S$. The case for evidence-based pharmaceutical care. Research in social \& administrative pharmacy: RSAP 2015; 11(3): e146-e147.

15. DeYoung JL, Vanderkooi ME, Barletta JF. Effect of barcode-assisted medication administration on medication error rates in an adult medical intensive care unit. $\mathrm{Am} \mathrm{J}$ Health Syst Pharm 2009; 66(12): 1110-1115.

16. Mansour M, James $V$, Edgley $A$. Investigating the safety of medication administration in adult critical care settings. Nurs Crit Care 2012; 17(4): 189-197.

17. Colpaert $K$, Claus $B$, Somers $A$, Vandewoude $K$, Robays $H$, Decruyenaere J. Impact of computerized physician order entry on medication prescription errors in the intensive care unit: a controlled cross-sectional trial. Crit Care 2006; 10(1): R21.

18. Leila Bahrani TE, Peter Höglund, Patrik Midlöv. The rate and nature of medication errors among elderly upon admission to hospital after implementation of clinical pharmacist-led medication reconciliation. Eur J Hosp Pharm 2014; 21(3): 156-160.

19. Jones KJ, Cochran GL, Xu L, Skinner A, Knudson A, Hicks. RW. The Association Between Pharmacist Support and Voluntary Reporting of Medication Errors: An Analysis of MEDMARX® Data. In: Henriksen K, Battles JB, Keyes MA, Grady ML, editors. Advances in Patient Safety: New Directions and Alternative Approaches Rockville (MD): Agency for Healthcare Research and Quality; 2008.

20. Garrouste-Orgeas M, Philippart F, Bruel C, Max A, Lau $N$, Misset $B$. Overview of medical errors and adverse events. Ann Intensive Care 2012; 2(1): 2. 